\title{
PENGARUH TERAPI REIKI TERHADAP PENURUNAN KADAR GLUKOSA DARAH SEWAKTU PADA LANSIA PENDERITA DIABETES MELITUS DI PANTI SOSIAL TRESNA WERDHA TERATAI PALEMBANG TAHUN 2017
}

\author{
Zakinah Arlina ${ }^{1}$, Riawati $^{2}$ \\ Program Studi DIII Keperawatan STIKES Mitra Adiguna Palembang \\ Komplek Kenten Permai Blok J No 9-12 Bukit Sangkal Palembang 30114 \\ Email : Linasalam2004@gmail.com
}

\begin{abstract}
Abstrak
Reiki merupakan terapi komplementer untuk menurunkan kadar glukosa darah. Terapi ini menggunakan energi alami yang memiliki karakter yang lembut, tetapi memiliki vibrasi/getaran cukup kuat sehingga sangat baik untuk menyembuhkan berbagai macam penyakit. Pemberian terapi reiki di berikan selama 20-30 menit. Selanjutnya dilakukan pengukuran kadar glukosa darah untuk mengetahui pengaruh dari terapi reiki tersebut. Tujuan penelitian untuk mengetahui Pengaruh Terapi Reiki terhadap Penurunan Glukosa Darah Sewaktu pada Lansia Penderita Diabetes Melitus di Panti Sosial Tresna Werdha Teratai Palembang Tahun 2017. Desain penelitian Pre Experimental dengan pendekatan One group pre test-post test design. Sejumlah 16 sampel dipilih dengan teknik purposive sampling. Terapi dilakukan selama empat belas hari. Hasil penelitian uji statistik diperoleh nilai $p$ sebesar 0,000 lebih kecil dari nilai a=0.05 sehingga Ho diterima dan Ha ditolak, berarti dapat disimpulkan bahwa ada pengaruh terapi reiki terhadap penurunan kadar glukosa darah sewaktu pada lansia penderita diabetes melitus. Saran yang ditunjukkan untuk tenaga kesehatan adar lebih meningkatkan pelayanan kesehatan terutama pada lansia yang mengalami diabetes melitus di Panti Sosial Tresna Werdha Teratai Palembang, salah satunya dengan terapi reiki.
\end{abstract}

\section{Kata kunci : Lansia, Diabetes Melitus, Gula darah, Terapi Reiki}

\begin{abstract}
Reiki is a complementary therapy to lower blood glucose levels. This therapy uses natural energy that has a gentle character, but has a strong enough vibration so that it is very good for curing various diseases. Reiki therapy is given for 20-30 minutes. Furthermore, blood glucose levels were measured to determine the effect of the reiki therapy. The purpose of the study was to determine the effect of Reiki therapy on reducing blood glucose while in the elderly with diabetes mellitus at the Tresna Werdha Teratai Social Home in Palembang in 2017. Pre Experimental research design with a One group pre test-post test design approach. A total of 16 samples were selected by purposive sampling technique. Therapy was carried out for fourteen days. The results of the statistical test showed that the $p$ value of 0.000 was smaller than the value of $=0.05$ so that Ho was accepted and Ha was rejected, meaning that it can be concluded that there is an effect of reiki therapy on reducing blood glucose levels in the elderly with diabetes mellitus. Suggestions for health workers are to improve health services, especially for the elderly who have diabetes mellitus at the Tresna Werdha Teratai Social Home in Palembang, one of which is reiki therapy.
\end{abstract}

Keywords: Elderly, Diabetes Mellitus, Blood sugar, Reiki Therapy

Jurnal Kesehatan dan Pembangunan, Vol. 11, No. 22, Juli 2021 


\section{PENDAHULUAN}

Diabetes Melitus adalah kumpulan gejala yang timbul pada seseorang akibat peningkatan kadar glukosa darah yang disebabkan oleh kekurangan insulin baik absolute maupun relatif. Penyakit ini dapat menyerang siapa saja dari berbagai kelompok umur dan kelompok sosial ekonomi. Pada lansia dengan bertambahnya usia akan mengakibatkan penurunan fungsi organ sehingga akan menimbulkan berbagai macam penyakit, diantaranya gangguan sirkulasi darah, gangguan hormonal, gangguan persendian dan berbagai macam neoplasma. (Syafrudin, DKK. 2011).

Menurut data WHO, dunia kini didiami oleh 172 juta penderita DM (2000) akan meningkat 2 kali, 366 juta pada tahun 2030. (Bustan, M. Nadjib. 2015:119). Berdasarkan estimasi International Diabetes Federation (IDF) tahun 2002 terdapat 177 juta penduduk dunia yang menderita DM dan diprediksi 25 tahun mendatang akan meningkat menjadi 300 juta jiwa (Sudoyo, et al. 2006). Saat ini ada sekitar 172 juta orang mengidap diabetes di seluruh dunia, dengan penyebarannya 7.020.000 orang di daerah Afrika, 15.188.000 orang di daerah Mediterania, 33.016.000 orang di daerah Amerika, 33.332.000 orang di daerah Eropa, 46.903.000 orang di Asia Tenggara, 35.771.000 di daerah Pasifik Utara dan di Indonesia terdapat sekitar 8.426 .000 orang menderita DM.

DM ditandai dengan hiperglikemia yang dapat mengakibatkan gangguan organ tubuh seperti mata, jantung, dan ginjal. Ada lima komponen penatalaksanaan diabetes tipe 2, yaitu terapi nutrisi (diet), latihan fisik, pemantauan, terapi farmakologi dan pendidikan (Smeltzer, et al, 2008).

Di samping terapi medis, saat ini telah berkembang terapi komplementer untuk membantu mengatasi permasalahan kesehatan pasien. Terapi komplementer adalah terapi yang sifatnya melengkapi terapi medis dan telah terbukti manfaatnya (Conn, Hollister, dan Arnold, 2001). Salah satu terapi komplementer yang diklasifikasikan oleh National Center of Com-plementary and Alternative medicine (NCCAM) sebagai terapi "energy medicine" adalah Reiki. (Jurnal Keperawatan Indonesia, Volume 14, No. 2, Juli 2011: 113-120).

Pemberian terapi reiki di berikan selama 20-30 menit. Selanjutnya dilakukan pengukuran kadar glukosa darah untuk mengetahui pengaruh dari terapi reiki tersebut. Tujuan terapi reiki adalah menormalkan aktivitas insulin dan kadar glukosa darah untuk mengurangi komplikasi yang ditimbulkan akibat DM.

Menurut data dari Panti Sosial Tresna Werdha Teratai Palembang pada tahun 2015 lansia laki-laki berjumlah 28 orang dan lansia perempuan berjumlah 33 orang, pada tahun 2016 lansia laki-laki berjumlah 27 orang dan lansia perempuan berjumlah 41 orang, dan pada tahun 2017 lansia laki-laki berjumlah 25 orang dan lansia perempuan berjumlah 45 orang, dan petugas panti laki-laki berjumlah 5 orang dan perempuan berjumlah 5 orang.

Berdasarkan uraian diatas pemberian terapi reiki dapat menurunkan kadar glukosa darah sewaktu pada lansia penderita Diabetes Melitus maka penulis tertarik untuk melakukan penelitian dengan judul "Pengaruh Terapi Reiki Terhadap Penurunan Kadar Glukosa Darah Sewaktu Pada Lansia Penderita Diabetes Melitus".

\section{METODE PENELITIAN}

\section{Desain Penelitian}

Rancangan penelitian mengggunakan metode eksperimen dengan Pre Experimental Design dengan pendekatan One group pre test-post test design. Dalam penelitian ini peneliti ingin mempelajari tentang pengaruh terapi reiki terhadap penurunan glukosa darah sewaktu pada lansia penderita diabetes melitus.

\section{Format Penelitian}

Rancangan penelitian ini adalah penelitian deskriptif kuantitatif. Deskriptif 
adalah metode penelitian yang dilakukan dengan tujuan utama untuk membuat gambaran atau deskripsi tentang suatu keadaan secara objektif, yang sering digunakan dalam pelayanan kesehatan, untuk melaksanakan penelitian atau pengumpulan data untuk menguji hipotesis (Notoatmodjo, 2010).

Kuantitatif adalah data yang berhubungan dengan angka-angka baik yang diperoleh dari hasil pengukuran maupun dari nilai suatu data yang diperoleh dengan jalan mengubah data kualitatif kedalam kuantitatif, misalnya skor dari hasil tes (Notoadmodjo, 2010).

\section{Waktu Penelitian}

Penelitian ini dilakukan pada tanggal 22 April - 6 Mei 2017 di Panti Sosial Tresna Werdha Teratai Palembang Tahun 2017.

\section{Tempat Penelitian}

Penelitian ini dilakukan di Panti Sosial Tresna Werdha Teratai Palembang Tahun 2017.

\section{Data \\ Data Primer}

Dalam penelitian ini peneliti menggunakan data primer. Data primer yaitu data/sumber informasi yang langsung berasal dari yang mempunyai wewenang dan bertanggung jawab terhadap data tersebut atau seorang yang dianggap mampu dan dapat memberikan informasi-informasi yang di butuhkan (Notoatmodjo, 2012). Dalam penelitian ini menggunakan data primer yang didapat secara langsung dari responden dengan menggunakan alat bantu berupa lembar observasi.

\section{Data sekunder}

Data sekunder yaitu data atau sumber informasi yang bukan dari tangan pertama dan yang bukan mempunyai wewenang dan tanggung jawab terhadap informasi atau data tersebut (Notoatmodjo, 2012). Penelitian menggunakan data sekunder yang diperoleh dengan melakukan studi perpustakaan berupa buku maupun media elektronik berupa internet yang berkaitan dengan penelitian yang dilakukan.

\section{Populasi dan sampel \\ Populasi}

Populasi penelitian adalah keseluruhan objek penelitian atau objek yang di teliti (Notoatmodjo, 2012). Populasi dalam penelitian ini adalah 70 orang lansia di Panti Sosial Tresna Werdha Teratai Palembang Tahun 2017.

\section{Sampel}

Sampel penelitian adalah sebagian yang diambil dari keseluruhan objek yang diteliti dan sanggup mewakili seluruh populasi (Notoatmodjo, 2012). Sampel yang diteliti adalah 16 orang lansia yang mengalami diabetes melitus di Panti Sosial Tresna Werdha Teratai Palembang Tahun 2017.

\section{Teknik pengambilan sampel}

Sampel penelitian adalah sebagian yang diambil dari keseluruhan objek yang diteliti dan dianggap mewakili seluruh populasi (Notoatmodjo, 2010).

Pengambilan sampel pada penelitian ini dilakukan non probability sampling secara purposive sampling didasarkan pada suatu pertimbangan tertentu yang dibuat oleh peneliti sendiri, berdasarkan ciri atau sifatsifat populasi yang sudah diketahui sebelumnya (Notoatmodjo, 2012).

\section{HASIL PENELITIAN DAN PEMBAHASAN}

Analisis Univariat

Karakteristik Lokasi Penelitian

Panti Sosial Tresna Werdha Teratai Palembang Tahun 2017 
Karakteristik responden

Karakteristik responden akan di distribusikan berdasarkan umur

Tabel 1

Distribusi responden berdasarkan umur

\begin{tabular}{cccc}
\hline No & Umur & Jumlah & Frekuensi \\
\hline 1. & $\begin{array}{l}60-64 \\
\text { Tahun }\end{array}$ & 3 & $18,75 \%$ \\
\hline 2. & $\begin{array}{l}65-69 \\
\text { Tahun }\end{array}$ & 5 & $31,25 \%$ \\
\hline 3. & $\begin{array}{l}70-74 \\
\text { Tahun }\end{array}$ & 6 & $37,5 \%$ \\
\hline 4. & $\begin{array}{l}75-79 \\
\text { Tahun }\end{array}$ & 0 & $0 \%$ \\
\hline 5. & $\begin{array}{l}80-84 \\
\text { Tahun }\end{array}$ & 2 & $12,5 \%$ \\
\hline & Total & 16 & $100 \%$ \\
\hline
\end{tabular}

Berdasarkan tabel 1 di atas responden berumur 60-64 Tahun sebanyak 3 orang (18,75\%), responden berumur 65-69 Tahun sebanyak 5 orang $(31,25 \%)$, responden berumur 70- 74 Tahun sebanyak 6 orang (37,5\%), responden berumur 75- 79 Tahun sebanyak 0 orang $(0 \%)$ dan responden berumur 80- 84 Tahun sebanyak 2 orang $(12,5 \%)$.

\section{Kadar Glukosa Darah Sewaktu Sebelum diberikan Terapi Reiki}

Kadar glukosa darah sewaktu sebelum diberikan Terapi Reiki dalam penelitian ini di bagi menjadi 3 kategori yaitu ideal ( skor: $80-144 \mathrm{mg} / \mathrm{dL}$ ), sedang (145$179 \mathrm{mg} / \mathrm{dL}$ ) dan buruk (180 mg/dL). Jumlah responden dalam penelitian ini sebanyak 16 orang. Hasil analisis univariat kadar glukosa darah sewaktu sebelum diberikan terapi reiki dapat dilihat pada tabel di bawah ini:
Tabel 2

Distribusi Frekuensi berdasarkan Tingkat Kadar Glukosa Darah Sewaktu Sebelum diberikan Terapi Reiki di Panti Sosial Tresna Werdha Teratai Palembang Tahun 2017

\begin{tabular}{cccc}
\hline No & $\begin{array}{c}\text { Kadar Glukosa } \\
\text { Darah Sewaktu } \\
\text { Sebelum } \\
\text { diberikan } \\
\text { Terapi Reiki }\end{array}$ & Jumlah & Frekuensi \\
\hline 1. & $\begin{array}{c}\text { Ideal (80-144 } \\
\text { mg/dL) }\end{array}$ & 0 & 0 \\
\hline 2. & $\begin{array}{c}\text { Sedang (145- } \\
179 \mathrm{mg} / \mathrm{dL})\end{array}$ & 9 & $56,25 \%$ \\
\hline 3. & $\begin{array}{c}\text { Buruk (180 } \\
\text { mg/dL) }\end{array}$ & 7 & $43,75 \%$ \\
\hline & Jumlah & 16 & $100 \%$ \\
\hline
\end{tabular}

Dari tabel diatas diketahui bahwa dari 16 respondensebelum diberikan terapi reiki sebanyak $9(56,25 \%)$ responden mengalami kadar glukosa darah sewaktu ringan dan 7 $(43,75 \%)$ responden mengalami kadar glukosa darah sewaktu berat.

\section{Kadar Glukosa Darah Sewaktu Sesudah diberikan Terapi Reiki}

Kadar glukosa darah sewaktu sesudah diberikan Terapi Reiki dalam penelitian ini di bagi menjadi 3 kategori yaitu ideal ( skor: 80 $144 \mathrm{mg} / \mathrm{dL})$, sedang (145-179 mg/dL) dan buruk $(180 \mathrm{mg} / \mathrm{dL})$. Jumlah responden dalam penelitian ini sebanyak 16 orang. Hasil analisis univariat kadar glukosa darah sewaktu sebelum diberikan terapi reiki dapat dilihat pada tabel di bawah ini: 
Tabel 3

Distribusi Frekuensi berdasarkan

Tingkat Kadar Glukosa Darah Sewaktu

Sesudah diberikan Terapi Reiki di Panti

Sosial Tresna Werdha Teratai Palembang Tahun 2017

\begin{tabular}{cccc}
\hline Kadar & & \\
No & $\begin{array}{l}\text { Glukosa } \\
\text { Darah } \\
\text { Sewaktu } \\
\text { Sesudah } \\
\text { diberikan } \\
\text { Terapi Reiki }\end{array}$ & Jumlah & Frekuensi \\
\hline 1. & $\begin{array}{c}\text { Ideal (80-144 } \\
\text { mg/dL) }\end{array}$ & 7 & $43,75 \%$ \\
\hline 2. & $\begin{array}{c}\text { Sedang (145- } \\
179 \mathrm{mg} / \mathrm{dL})\end{array}$ & 8 & $50 \%$ \\
\hline 3. & $\begin{array}{c}\text { Buruk (180 } \\
\text { mg/dL) }\end{array}$ & 1 & $6,25 \%$ \\
\hline & Jumlah & 16 & $100 \%$ \\
\hline
\end{tabular}

Dari tabel diatas diketahui bahwa dari 16 responden sesudah diberikan terapi reiki sebanyak $7 \quad(43,75 \%)$ responden mengalami kadar glukosa darah sewaktu ideal, 8 (50\%) responden mengalami kadar glukosa darah sewaktu ringan dan $1(6,25 \%)$ responden mengalami kadar glukosa darah berat.

\section{Analisis Bivariat}

Analisis Hasil Pengaruh Terapi Reiki terhadap Penurunan Kadar Glukosa Darah Sewaktu pada Lansia Penderita Diabetes Melitus

Metode pengukuran dalam penelitian ini menggunakan uji t berpasangan (paired sample t test). Analisis data yang dilakukan untuk menguji apakah data menunjukkan terdistribusi normal jika a $\geq 0,05$ hasil yang diperoleh merupakan data berpasangan yaitu sebelum dan sesudah tindakan oleh karena penelitian ini menggunakan uji t berpasangan (paired sample t test). Hasil uji normalitas diperoleh nila 0,200 yang berarti data distribusi normal
Tabel 4

Hasil analisa statistik Paired Samples $\mathbf{t}$ Test

\begin{tabular}{ccccc}
\hline Variabel & Mean & SD & Df & $\begin{array}{c}\boldsymbol{p} \\
\text { value }\end{array}$ \\
\cline { 1 - 3 } Pre test & 167,75 & 20,844 & & \\
\cline { 1 - 3 } Post test & 152,38 & 15,547 & 0,001 \\
\hline
\end{tabular}

Berdasarkan data diatas diketahui bahwa nilai rata-rata kadar glukosa darah sewaktu sebelum dilakukan terapi reiki yaitu 167,75 dan nilai rata-rata kadar glukosa darah sewaktu sesudah dilakukan terapi reiki yaitu 152,38. Standar deviasi sebelum diberikan terapi reiki yaitu 20,844 dan setelah diberikan terapi reiki yaitu 15,547 . Hasil uji statistik diperoleh nilai $p$ sebesar 0,001 lebih kecil dari nilai a $=0,05$ sehingga $\mathrm{Ho}$ diterima $\mathrm{Ha}$ ditolak. Berarti dapat disimpulkan bahwa ada pengaruh terapi reiki terhadap penurunan kadar glukosa darah sewaktu pada lansia penderita diabetes melitus.

\section{PEMBAHASAN}

Penelitian ini dilakukan di Panti Sosial Tresna Werdha Teratai Palembang Tahun 2017 pada tanggal 22 April- 6 Mei 2017. Populasi penelitian ini adalah semua lansia yang menderita diabetes melitus di Panti Sosial Tresna Werdha Teratai Palembang Tahun 2017 pada saat penelitian, jumlah sampel dalam penelitian ini berjumlah 16 orang. Kemudian diolah dengan cara analisis statistik, pengkodean pemasukan data. Setelah itu dilakukan analisis univariat, selanjutnya data diuji dengan menggunakan uji paired sample t test untuk mengetahui ada/tidaknyapengaruh terapi reiki terhadap penurunan kadar glukosa darah sewaktu pada lansia penderita diabetes melitus. Dengan kriteria pengujian berdasarkan probalitas yaitu $p$ value $\geq 0,05$ maka Ho ditolak dan jika $p$ value $\leq 0,05$ maka Ho diterima. 


\section{Analisis Pengaruh Terapi Reiki Terhadap Penurunan Kadar Glukosa Darah Sewaktu pada Lansia Penderita Diabetes Melitus}

Berdasarkan hasil penelitian yang menggunakan uji paired sample $t$ test didapatkan nilai rata-rata kadar glukosa darah sewaktu sebelum dilakukan terapi reiki yaitu 167,75 dan nilai rata-rata kadar glukosa darah sewaktu sesudah dilakukan terapi reiki yaitu 152,38. Standar deviasi sebelum diberikan terapi reiki yaitu 20,844 dan setelah diberikan terapi reiki yaitu 15,547 . Hasil uji statistik diperoleh nilai $p$ sebesar 0,001 lebih kecil dari nilai $\mathrm{a}=0,05$ sehingga Ho diterima $\mathrm{Ha}$ ditolak. Berarti dapat disimpulkan bahwa ada pengaruh terapi reiki terhadap penurunan kadar glukosa darah sewaktu pada lansia penderita diabetes melitus.

Hasil penelitian ini sejalan dengan hasil penelitian Ester Inung Sylvia (2011) dengan judul Penurunan Kadar Glukosa Darah Sewaktu Melalui Terapi Reiki Pada Pasien Diabetes Melitus Tipe 2 di Klub Diabetes Instalasi Rehabilitasi Medis RSUP Fatmawati, Jakarta. Desain penelitian yang digunakan adalah pra-eksperimental dengan pendekatan the one-group pretest-posttest design (before and after) menggunakan teknik purposif sampling untuk pengambilan sampelnya. Sampel berjumlah 18 responden.

Terapi Reiki dilakukan dengan dua metode, secara langsung dan dari jarak jauh (distant healing) yang diberikan selama 30 hari. Terapi Reiki dilakukan oleh peneliti dibantu oleh praktisi Reiki khususnya dalam transfer energi. Instrumen yang digunakan untuk mengukur kadar glukosa darah adalah glukometer. Hasil penelitian menunjukkan ada perbedaan yang bermakna antara KGDS sebelum dan setelah intervensi Reiki ( $\mathrm{p}=$ $0,000 ; \alpha=0,05)$ dan mempunyai pengaruh yang signifikan dalam menurunkan Kadar Glukosa Darah Sewaktu Pada Pasien Diabetes Melitus Tipe $2(p=0,000 ; \alpha=0,05)$.

Tetapi hasil Penelitian ini tidak sejalan dengan pernyataan American Academy of
Neurology (AAN) (2011) Penulis mencatat baik tramadol dan dextromethorphan berkaitan dengan efek samping mendasar termasuk sedasi pada kedua obat, mual dan konstipasi pada tramadol, kedua obat ini juga tercatat menimbulkan sindrom nyeri baru berupa nyeri kepala. Penggunaan jangka panjang dapat menyebabkan intoleransi dan memerlukan kenaikan dosis. Dari intervensi farmakologi, direkomendasikan penggunaan krim capsaicin dan spray isosorbide dinitrate untuk manajemen nyeri neuropati diabetes meskipun tercatat beberapa pasien intoleran terhadap efek samping berupa nyeri terbakar pada saat terkena air hangat atau dalam cuaca yang cukup panas. Clonidine, pentoxifylline dan mexiletine tidak dipertimbangkan untuk digunakan.

Terapi non-farmakologi lain yang direkomendasikan adalah TENS (trancutaneous electricalnerve stimulation) tetapi bukan pada area elektromagnetik, terapi laser intensif rendah atau terapi Reiki. Weak evidence (Level C). Penambahan venlafexine terhadap gabapentin untuk mencapai respons lebih baik Patch lidoderm sebagai terapi nyeri neuropati diabetes. Insufficient evidence (level $\boldsymbol{U}$ ). Penulis mencatat bukti yang kurang mendukung atau menyangkal penggunaan antikonvulsan topiramate, antidepresan imipramine, fluoxetine atau kombinasi nortriptyline dan fluphenazine. Mirip di atas karena kurangnya data penggunaan vitamin dan $\alpha$ lipoic acid atau kombinasi amitriptyline dengan terapi elektroterapi.

Ditemukan efek plasebo penurunan efek nyeri dari 0 hingga $50 \%$, dinyatakan pula nyeri neuropati diabetes merupakan penyakit kronis dan tidak ada data efikasi penggunaan jangka panjang karena umumnya penelitian hanya berdurasi 2-20 minggu.

Hal ini dilandaskan pada teori, pemberian terapi reiki di berikan selama 2030 menit dan lama waktu penyembuhan sangat tergantung pada tingkat penyakit. Untuk penyakit ringan bisa sembuh dengan hitungan hari, sedangkan penyakit yang 
sedang bisa sembuh dalam hitungan minggu, dan penyakit parah bisa sembuh dalam hitungan bulan. (Dewantara, Rudy: 2016). Keunggulan alat ini adalah kemampuannya memperbaiki sistem syaraf didalam tubuh yang tidak bisa tersentuh oleh pijatan tangan manusia. Tidak mempunyai efek samping apabila dengan pemakaian yang benar.

\section{KESIMPULAN}

Dari hasil yang telah dilakukan dapat disimpulkan bahwa:

1. Distribusi frekuensi sebelum diberikan terapi reiki sebanyak $9 \quad(56,25 \%)$ responden mengalami kadar glukosa darah sewaktu ringan dan $7(43,75 \%)$ responden mengalami kadar glukosa darah sewaktu berat.

2. Distribusi frekuensi sesudah diberikan terapi reiki sebanyak $7 \quad(43,75 \%)$ responden mengalami kadar glukosa darah sewaktu ideal, 8 (50\%) responden mengalami kadar glukosa darah sewaktu ringan dan $1 \quad(6,25 \%)$ responden mengalami kadar glukosa darah berat.

3. Berdasarkan hasil penelitian yang menggunakan uji paired sample $t$ test didapatkan nilai rata-rata kadar glukosa darah sewaktu sebelum dilakukan terapi reiki yaitu 167,75 dan nilai rata-rata kadar glukosa darah sewaktu sesudah dilakukan terapi reiki yaitu 152,38 . Standar deviasi sebelum diberikan terapi reiki yaitu 20,844 dan setelah diberikan terapi reiki yaitu 15,547. Hasil uji statistik diperoleh nilai $p$ sebesar 0,001 lebih kecil dari nilai $a=0,05$ sehingga Ho diterima Ha ditolak. Berarti dapat disimpulkan bahwa ada pengaruh terapi reiki terhadap penurunan kadar glukosa darah sewaktu pada lansia penderita diabetes melitus

\section{SARAN}

1. Bagi Tenaga Kesehatan

Diharapkan agar lebih meningkatkan pelayanan kesehatan terutama pada lansia yang mengalami diabetes melitus di Panti Sosial Tresna Werdha Teratai Palembang, salah satunya yaitu dengan terapi reiki.
2. Bagi Instansi Pendidikan

Hasil penelitian ini diharapkan dapat menjadi sumber bacaan untuk menambah ilmu pengetahuan, informasi bagi peserta didik dimasa yang akan datang dan digunakan untuk melengkapi referensi kepustakaan STIKES Mitra Adiguna Palembang.

3. Bagi Peneliti Selanjutnya

Diharapkan pada peneliti lain untuk meneliti dengan judul yang sama tetapi dengan memperhatikan hari dan waktu terapi di perbaiki lagi.

\section{DAFTAR PUSTAKA}

Buku Petunjuk Penggunaan Reiki Mesin terapi Digital. 2014. Teknologi dan Ilmu Pengetahuan Modern Digabungkan dengan Pengobatan Cina.

Bustam, M. Nadjib. 2015. Manajemen Pengendalian Penyakit Tidak Menular. Jakarta: Rineka Cipta.

Damayanti, Santi. 2015. Diabetes Melitus dan Penatalaksanaan Keperawatan. Yogyakarta: Nuha Medika.

Dewantara, Rudy. 2012.

http://terapireiki.com/ di unduh tanggal 20

Desember 2016.

Doenges, Marilynn E. DKK. 2012. Rencana Asuhan Keperawatan Pedoman Untuk Perencanaan dan Pendokumentasian Perawatan Pasien Edisi 3. Jakarta: EGC

Hermawanto, Hery. 2010. Biostatistika Dasar, Dasar-dasar Statistik dalam Kesehatan. Jakarta:Trans Info Media.

http://sehat.link/data-prevalensi-penderitadiabetes-di-indonesia.info di unduh tanggal 18 Januari 2017

Irianto, Koes. 2014. Epidemiologi Penyakit Menular \& Tidak menular panduan klinis. Bandung: Alfabeta. hal 312320.

Kushariyadi. 2012. Asuhan Keperawatan pada Klien Lanjut Usia. Jakarta: Salemba Medika. 
Notoatmodjo, Soekidjo. 2007. Kesehatan Masyarakat Ilmu \& Seni. Jakarta: Rineka Cipta. hal 279-293.

Notoatmodjo, Soekidjo. 2010. Metodelogi Penelitian Kesehatan. Jakarta: Rineka Cipta.

Notoatmodjo, Soekidjo. 2012. Metodelogi Penelitian Kesehatan. Jakarta: Rineka Cipta.

Pranadila.com/alat-terapi-digital-reikiuntuk-kesehatan.html di unduh tanggal 25 Januari 2017

R. Hasdianah H. 2012. Mengenal Diabetes Melitus Pada Orang Dewasa dan Anak-anak dengan Solusi Herbal. Yogyakarta: Nuha Medika

Sari, Riska Indah. 2016. Kadar Gula Darah pada pasien Diabetes Melitus yang diberikan Intervensi Senam Kaki Diabetes di RS Siti Khadijah Palembang Tahun 2016. (Skripsi)

Sugiono. 2016. Metode Penelitian Kuantitatif, Kualitatif, dan $R \& D$. Bandung: Alfabeta.

Sunaryo. DKK. 2016. Asuhan Keperawatan Gerontik. Yogyakarta: CV Andi Offset.

Syafrudin, DKK. 2011. Himpunan Penyuluhan Kesehatan (Pada Remaja, Keluarga, Lansia dan Masyarakat). Jakarta: Trans Info Media. hal 189-192. 